Editorial

\title{
Memories from Dr. Joseph dello russo about the first laser
}

\section{Editorial}

“Ok, Send Me One!" Personal memories from Dr. Joseph Dello Russo By 1983 I had given up doing radial keratotomy, especially after I heard that Dr. Steven Trokel started to work on a laser to perform laser vision correction with a device called Excimer laser. So I waited... In 1987 I saw an announcement in "Ophthalmology Times" about the first world conference devoted to Excimer laser, which I attended along with about twenty others. The conference was held at Tulane Hospital with the laser located in a trailer in the parking lot.

There were two separate groups of doctors: skeptical professors and the non-academic doctors (like myself). As a suburban doctor I must admit that I fell in love with the concept of laser correction. After the presentation I immediately gave the CEO of Visx a check for $\$ 25 \mathrm{~K}$, the ten percent deposit to purchase their first laser. He was delightedly bewildered with their first check. Imagine that! He told me he had to figure out a contract for me. He had never done one before. Myself and nine other doctors became FDA investigators. It took us six years to get the approval of the Visx laser, which happened in 1996. The approval process included many national and international trips; presentations of our experiences at meetings; and articles in professional journals.

Thank goodness that the technology proved to be sound. Of course, we started with PRK. How else were we going to change the shape of the cornea? We aimed the laser at the surface of the cornea. Of course. Despite the pain and delayed healing, patients loved PRK results. They were warned that there would be some pain and it would take a few days to see well.

During the 1992 international meeting in Crete, Greece hosted by Dr. Paliakaris, we were advised by him to stop operating on the surface of the cornea, but instead operate inside of it. He explained to us that we should use a microkeratome to cut off the "top" of the

\author{
Volume 2 Issue 6 - 2015 \\ Joseph Dello Russo \\ Dello Russo Laser Vision, USA
}

Correspondence: Joseph Dello Russo, Dello Russo LaserVision, I North Washington Ave Bergenfield New Jersey, USA, Tel 2159175007, Email elyapustina@dellorusso.com

Received:September 12, 2015 | Published: September 21, 2015

cornea, reshape the "bed" and then put the top back on. And though I felt the idea was not thought through enough, Dr. Paliskaris eventually developed this concept into a flap with a hinge and thus LASIK evolved. Over the years I got very close with Dr. Trokel, whether we met in my LASIK office or we traveled abroad for international conferences. He used to be delighted in telling other doctors about my reaction, when in 1987 he showed me the laser in the Tulane parking lot. He said that I approached the laser suspiciously, circled the laser with my chin in my hand, kicked the tires of the portable laser and then proclaimed: "Ok, send me one!" And they did.

\section{Acknowledgments}

None.

\section{Conflicts of interest}

The author declares that there no conflicts of interest.

\section{Funding}

None. 